\title{
Major contribution of reduced upper ocean oxygen mixing to global ocean deoxygenation in an Earth System Model
}

\author{
Damien Couespel ${ }^{1}$,Marina Lévy ${ }^{1}$ and Laurent Bopp ${ }^{2}$ \\ ${ }^{1}$ LOCEAN-IPSL, Sorbonne Université / CNRS / MNHN / IRD, Paris, France. \\ ${ }^{2}$ LMD-IPSL, École Normale Supérieure / PSL Research University/CNRS / École Polytechnique / \\ Sorbonne Université, Paris, France.
}

\section{Key Points:}

- $\mathrm{O}_{2}$ subduction and respiration diagnostics are used to quantify the drivers of deoxygenation at the scale of ocean basins

- Reduced solubility, reduced subduction and reduced export explain 50\%, 150\% and $-100 \%$ of global deoxygenation, respectively.

- Reduced mixing explains $75 \%$ of reduced subduction but locally the largest changes in subduction result from shifts in Ekman pumping patterns.

Corresponding author: Damien Couespel, damien.couespel@locean-ipsl.upmc.fr 


\section{Abstract}

We present a quantitative analysis of deoxygenation drivers applied to an Earth System Model and easily transposable to large model ensembles. The preindustrial ocean breathes oxygen in in polar regions and in subtropical gyres, and breathes oxygen out in the equatorial band and in subpolar gyres. Under a high- $\mathrm{CO}_{2}$ emission scenario for the 21st century, small deviations of these large natural oxygen fluxes cause global deoxygenation. We attribute half of this trend to a decrease in oxygen solubility. The other half is explained by negative trends in subduction and respiration, which largely cancel out each other. Moreover, $75 \%$ of the subduction decrease occurs through changes in mixing across the mixed-layer base. Our analysis also highlights strong modulations of subduction at the regional scale linked to shifts in wind patterns and associated Ekman pumping.

\section{Plain Language Summary}

Oxygen in the ocean has declined over the past 50 years and is expected to further decline by 2100 - a phenomenon referred to as Ocean Deoxygenation. This oxygen decrease may strongly impact marine habitat and enhance the production of nitrous oxyde, a powerful greenhouse gas. Dissolved oxygen is transported by ocean currents or mixed from the well-oxygenated surface to ocean depths where it is respired by marine life. Using a climate model, we find that half of ocean deoxygenation in the 21st century relates to lower oxygen solubility induced by ocean warming. In addition, we show that the rest of the decrease is caused by large changes in mixing and currents, partially compensated by lower respiration at depth. Finally, we show that most of ocean deoxygenation is due to reduced mixing and that shifts in wind patterns are modifying the oxygen supply at the local and regional scales.

\section{Introduction}

Observed changes in oxygen over the past 50 years have revealed that the content of dissolved oxygen $\left(\mathrm{O}_{2}\right)$ in the ocean is continuously declining (Helm et al., 2011; Stendardo \& Gruber, 2012; Schmidtko et al., 2017). Climate models predict a further decline by the end of the 21st century (Keeling et al., 2010; Bopp et al., 2013; Ciais et al., 2013; Cocco et al., 2013; Tagklis et al., 2017). Deoxygenation is one of the most worrying response of the ocean to climate change, as it may strongly alter marine habitats (Diaz 
\& Rosenberg, 2008; Vaquer-Sunyer \& Duarte, 2008) and increase the production of nitrous oxide, a greenhouse gas with high warming potential (Codispoti et al., 2001).

Deoxygenation ensues from a combination of competing processes (Keeling et al., 2010; Shepherd et al., 2017; Resplandy, 2018; Breitburg et al., 2018). Climate change is expected to increase the temperature and vertical stratification of the upper ocean, therefore decreasing oxygen solubility and limiting vertical oxygen exchanges. Increased stratification also reduces the supply of nutrients to the surface, and therefore the production and subsequent export of organic material, which eventually leads to less respiration at subsurface. Thus subsurface waters should receive less oxygen through physical supplies, because of reduced supply rates and reduced capacity to hold dissolved oxygen, but should also use less of that supplied oxygen for respiration.

There is a general agreement in climate projections that the decrease in respiration is overwhelmed by the more rapid decrease in oxygen supply (Bopp et al., 2013; Cabré et al., 2015; Tagklis et al., 2017; Bopp et al., 2017; Takano et al., 2018; Palter \& Trossman, 2018), at least along the 21st century (Fu et al., 2018). This unbalance leads to deoxygenation in the mesopelagic layer between the 1990s and the 2090s in all ten climatebiogeochemical models of the Coupled Model Intercomparison Project 5 (CMIP5) simulations (Bopp et al., 2013). There is also a wide consensus that solubility change explains about half of the deoxygenation in future climate projections (Bopp et al., 2017; Resplandy, 2018) and might explain some of the deoxygenation observed in recent decades (Schmidtko et al., 2017; Ito et al., 2017). But how changes in respiration and changes in physical oxygen supplies combine to explain the other half is more uncertain (Breitburg et al., 2018). The oxygen content of any water parcel in the ocean interior results from the history of this water parcel since it has left the surface, loaded with oxygen at a value close to saturation $\left(\mathrm{O}_{2}^{\text {sat }}\right)$. The local $\mathrm{O}_{2}$ deficit relative to the saturation value, termed AOU for Apparent Oxygen Utilization $\left(\mathrm{AOU}=\mathrm{O}_{2}^{\text {sat }}-\mathrm{O}_{2}\right)$, integrates the time-cumulative respiration along the trajectory from the area of formation (Deutsch et al., 2006). Changes in $\mathrm{O}_{2}^{\text {sat }}$ can be attributed to changes in solubility. Changes in AOU are more subtle to attribute because they incorporate changes in biology, changes in preformed oxygen at the mixed-layer base and changes in oxygen transport into the ocean interior (Deutsch et al., 2005), which makes it difficult to tease apart the different contributions, let alone the physical processes in play. 
In this study, we attempt to quantify the processes involved in the global decrease in oxygen supply to the ocean interior and the decrease in oxygen consumption in the interior, in an Earth System Model (ESM) from the CMIP5 generation, using an approach which builds upon the $\mathrm{O}_{2}$ decomposition into $\mathrm{O}_{2}^{\text {sat }}$ and AOU. Our diagnostics require knowledge of the seasonal changes in temperature, salinity, circulation and export production and can be easily applied to large ensembles of model simulations (and potentially to CMIP6 generation models) without the need for additional simulations, or for specific variables such as preformed tracers or remineralization rate.

The rational behind the $\mathrm{O}_{2}^{s a t}$ and AOU decomposition reflects that the oxygen content in the ocean interior depends on two key quantities: the amount of dissolved oxygen that leaves the surface, which in the following we refer to as oxygen subduction, and the amount of organic material that leaves the surface, because this export sets how much $\mathrm{O}_{2}$ is utilized by respiration in the interior. A natural boundary between the ocean interior where $\mathrm{O}_{2}$ is undersaturated and the upper part of the ocean which is in direct contact with the atmosphere and where $\mathrm{O}_{2}$ is close to saturation is the seasonal mixed-layer. Our main focus concerns the rates of physical oxygen exchanges and their sensitivity to climate change, a critical process which has been overlooked (Kwon et al., 2016; Tagklis et al., 2017; Bopp et al., 2017). Hence, our approach is to relate the changes in total oxygen content in the ocean interior to oxygen exchanges and organic matter export across the mixed-layer base. Along this line, our more specific objectives are to quantify oxygen subduction and respiration in the preindustrial ocean and their evolution along the 21st century. The physical processes contributing to total oxygen subduction include the kinematic subduction of water masses (Cushman-Roisin, 1987) and the diffusive subduction via $\mathrm{O}_{2}$ mixing (Karleskind et al., 2011; Kwon et al., 2016), which we estimate separately. Moreover, changes in oxygen subduction with climate change include a solubility component, related to changes in $\mathrm{O}_{2}^{\text {sat }}$, and a circulation component, related to changes in ocean circulation and in AOU. Our focus on exchanges across the mixed-layer enables us to tease apart these different contributions to deoxygenation.

\section{Material and methods}

Our estimates of oxygen subduction and export are based on offline diagnostics applied to simulations made with the full ESM IPSL-CM5A-LR (Dufresne et al., 2013) which are part of the CMIP5 climate change simulations. The diagnostics use monthly outputs 
from the coupled simulations. We use the convention that fluxes contributing to a gain of oxygen in the subsurface layer are positive. We use the expression subduction to describe an oxygen flux directed from the mixed-layer to the subsurface, causing subsurface oxygenation, and obduction for an oxygen flux in the opposite direction, causing subsurface deoxygenation. With this convention, a positive export flux of organic material, for instance by sedimentation, corresponds to a negative oxygen flux.

\subsection{Model and simulations}

The IPSL model core includes the marine biogeochemical model PISCES which has an explicit reresentation of the oxygen cycle (Aumont \& Bopp, 2006). We examined the changes between the 1990s and 2090s by combining the control simulation (CTL) and the climate change simulation (CC). The CTL simulation started from a preindustrial state in 1850, obtained after a 1000 year spin-up, and was applied a constant forcing (atmospheric concentrations of greenhouse gases, aerosols and land cover) for 250 years. The CC simulation started in 1850 from the same preindustrial state and was applied a forcing which followed historical data from 1850 to 2005, and followed the "business as usual scenario" RCP8.5 from 2006 to 2099. As for most CMIP5 ESM, oxygen is not fully equilibrated and a small drift is present. We used the CTL simulation to remove the drift from the climate change signal. The magnitude of this drift in the subsurface ocean represents $\sim 10 \%$ of the climate change signal in oxygen.

\subsection{Model evaluation and comparison with other CMIP5 projections}

A detailed comparison of observed and predicted subsurface oxygen content during the historical period in the suite of CMIP5 model is presented in Cabré et al. (2015) and Bao and Li (2016). It shows that the IPSL-CM5A-LR model simulates a reasonable mean state with respect to the other models. Its main weaknesses are 1) a too deep extend tropical hypoxia in the Pacific, shared with 4 other models (Cabré et al., 2015) and 2) too low oxygen levels in the deep ocean related to defficiencies in the representation of meridional overturning circulation (Bao \& Li, 2016).

The oxygen change simulated in the mesopelagic layer between the 1990s and 2090s in the IPSL-CM5A-LR RCP8.5 projection falls in the range of the mean change projected by the other CMIP5 models (Fig. S1a-d). It shows a pronounced decrease in oxygen con- 
tent over large parts of the temperate ocean, with patterns that are shared by most models and with maximum values in the North Pacific, and weaker changes in the subtropics.

Reductions in $\mathrm{O}_{2}^{s a t}$ are very robust across the CMIP5 model ensemble, and the main differences concern changes in AOU (Bopp et al., 2017). The general pattern is that AOU increases at mid-latitudes, inducing reduced $\mathrm{O}_{2}$ concentrations and reinforcing the change in $\mathrm{O}_{2}^{s a t}$. In contrast, at low latitudes the $\mathrm{O}_{2}^{\text {sat }}$ and $\mathrm{AOU}$ components compensate each other so that the resulting $\mathrm{O}_{2}$ change is relatively small compared with the individual components, but also more uncertain. The patterns of AOU changes in the IPSL-CM5ALR projection (Fig. S1c-f) are comparable to those of the model mean, however the amplitude of the change can be different in some regions, e.g. at mid-latitudes in the south Pacific, a region where there is a generally a poor agreement between models.

The main model difference, compared with the mean projection, is the strong oxygenation simulated in mesopelagic layer of the the Weddell Sea. The behavior of the IPSL model has already been identified as an outlier in this region (Little \& Urban, 2016), in particular because it is the only model that predicts a cooling and deeper mixed-layers along the coast in response to global warming (Leung et al. (2015), see also Fig. S3), a spurious pattern which is robust over an ensemble of simulations. Moreover, it should be noted that in this area, sea ice, which influences convection, is poorly represented even during the historical period Turner et al. (2013); Yang et al. (2016); Shu et al. (2015).

\subsection{Oxygen subduction}

Dissolved oxygen is exchanged between the surface and ocean interior through kinematic subduction $S_{k i n}$ (Cushman-Roisin, 1987), due to the subduction of water masses, and diffusive subduction, through mixing across the mixed-layer interface $S_{m i x}$ (Karleskind et al., 2011; Lévy et al., 2013; Bopp et al., 2015; Kwon et al., 2016):

$$
\begin{gathered}
S=S_{k i n}+S_{m i x} \\
S_{k i n}=\left(w_{h}+\overrightarrow{u_{h}} \cdot \overrightarrow{\nabla_{H}} h+\partial_{t} h\right) \cdot \overrightarrow{O_{h}} \\
S_{\text {mix }}=\left(k_{z} \partial_{z} O\right)_{h}+k_{l}\left(\overrightarrow{\nabla_{l} O}\right)_{h} \cdot \overrightarrow{\nabla_{l} h}
\end{gathered}
$$

where $h$ is the seasonally varying mixed-layer depth, the subscript ${ }_{h}$ means that the quantities are taken at depth $h, k_{z}$ and $k_{l}$ are the vertical and isopycnal mixing coefficients, 
respectively. For our offline diagnostics, we used monthly mean values of $h, O_{h}, \vec{u}_{h}$ and $w_{h}$.

The kinematic subduction of oxygen includes advection across the mixed-layer interface through vertical and horizontal advection, and entrainment/detrainment caused by temporal changes of $h$. It is proportional to the oxygen content at the mixed-layer base. Eddies in the IPSL-CM5A-LR model are parametrized with two terms, advection by a bolus velocity and diffusion along isopycnal surfaces (Gent \& McWilliams, 1990). The first term contributes to kinematic subduction while the second contributes to diffusive subduction. In our notation, the velocities $\vec{u}_{h}$ and $w_{h}$ include the sum of the coarse resolution model velocity and of the bolus velocities.

The diffusive subduction of oxygen includes vertical mixing and isopycnal mixing by eddies. It is proportional to the oxygen gradients across the mixed-layer base. The isopycnal mixing coefficient $k_{l}$ is given the constant value used in the model integration, $2000 \mathrm{~m}^{2} / \mathrm{s}$. The model vertical mixing coefficient $k_{z}$, on the other hand, varies between the surface mixed-layer $\left(>1 \mathrm{~m}^{2} / \mathrm{s}\right)$ and the ocean interior $\left(10^{-5} \mathrm{~m}^{2} / \mathrm{s}\right)$, and we used a value of $1.210^{-4} \mathrm{~m}^{2} / \mathrm{s}$ for our estimates of vertical mixing at the base of the mixedlayer, which is consistent with values used in similar offline integrations (Kwon et al. (2016); Bopp et al. (2015) and see Fig. S2 for an estimation of this value).

\subsection{Respiration}

Oxygen is used below the mixed-layer for decomposition of organic material (OM) and for nitrification of ammonium. Thus total oxygen respiration can be estimated from the fluxes of organic material $\left(F_{O M}\right)$ and ammonium $\left(F_{N H 4}\right)$ across the mixed-layer. We should note that organic matter (and ammonium) are also produced below the seasonal mixed-later and should thus contribute to the subsurface oxygen budget. We make the assumption that everything produced below the mixed-layer is also remineralized below the mixed-layer and that therefore the two contributions (oxygen production and oxygen utilization) cancel one another.

In our model, OM includes organic particles (large and small), dissolved organic matter, two sizes of phytoplankton and zooplankton. $F_{O M}$ includes the sedimentation of organic particles and the subduction of OM. $F_{N H 4}$ is the subduction of ammonium. Sedimentation is estimated from monthly concentrations of large and small organic par- 
ticles at depth $h$, multiplied by their respective sinking velocities (30 and $2 \mathrm{~m} /$ day respectively). Subduction of OM and ammonium is estimated using the same formulation than oxygen subduction, with monthly concentration of each tracers.

When oxygen is available, the breaking down of OM consumes 132/122 units of oxygen per unit of OM. Ammonium resulting from this process is then nitrified using 40/122 units of oxygen per unit of ammonium. Therefore under oxic conditions, 172/122 units of oxygen are consumed per unit of OM. In suboxic conditions, the breaking down of OM uses nitrate instead of oxygen (denitrification). In such cases, only 40/122 units of oxygen are consumed per unit of OM. We make the approximation that $10 \%$ of OM is remineralised in suboxic conditions (Aumont et al. (2015): $\sim 80 \mathrm{Tg} N / y$ is denitrified for $\sim 7 G t C / y$ of OM exported at 150 meters). Therefore $F_{O M}$ is converted to oxygen utilization using a constant Carbon to Oxygen ratio of $160 / 122(\approx 0.9 \times 172 / 122+0.1 \times$ $40 / 122)$, and $F_{N H 4}$ is converted to oxygen consumption using the ratio 40/122. In the following, we will use the term respiration $R=-160 / 122 \times F_{O M}-40 / 122 \times F_{N H 4}$ to refer to these fluxes that lead to oxygen consumption below the mixed-layer.

\subsection{1st century changes in oxygen fluxes}

The aim is to relate the oxygen content decrease in the ocean interior to the change in the fluxes across the mixed-layer (i.e. subduction and respiration), in order to sort apart the biological, thermodynamical and physical processes responsible for deoxygenation. In order to correct for the model drift, the change in oxygen content between the 90s (with $\bar{O}_{90 s}$ the mean over the 1990s) and year $y$ was evaluated as:

$$
\Delta O=\int_{z>h}\left(\left(O_{y}-\bar{O}_{90 s}\right)^{C C}-\left(O_{y}-\bar{O}_{90 s}\right)^{C T L}\right) d z
$$

We note $\Delta S_{m i x}, \Delta S_{k i n}$ and $\Delta R$ the changes in diffusive subduction, kinematic subduction and respiration. Each flux $F\left(S_{m i x}, S_{k i n}\right.$ and $\left.R\right)$ was cumulated from year 1990 until year $y$ in both the CTL and CC simulations and to correct for the model drift, we computed the difference between the two, which can be expressed as:

$$
\begin{gathered}
F_{y}=\int_{1990}^{y} F d t \\
\Delta F=F_{y}^{C C}-F_{y}^{C T L}
\end{gathered}
$$

Changes in subduction $\Delta S$ were further decomposed into change related to solubility or circulation. The contribution of solubility $\Delta S^{\text {sol }}$ was computed as the subduc- 
tion of $\Delta \mathrm{O}_{2}^{\text {sat }}$ by the mean circulation and across the mean seasonal mixed-layer depth of the 1990s. $O^{\text {sat }}$ was computed from monthly temperature and salinity following Garcia and Gordon (1992). The contribution of changes in circulation was estimated as the residual, $\Delta S^{\text {circ }}=\Delta S-\Delta S^{\text {sol }}$. It should be noted that circulation must be understood here in a broad sense since it includes the contribution of the changes in water mass subduction and also includes the subduction of the changes in AOU. Thus we can write:

$$
\begin{aligned}
\Delta S_{m i x} & =\Delta S_{m i x}^{s o l}+\Delta S_{m i x}^{c i r c} \\
\Delta S_{k i n} & =\Delta S_{k i n}^{s o l}+\Delta S_{k i n}^{c i r c}
\end{aligned}
$$

Using the hat notation for integration over the entire ocean, the different quantities are related with:

$$
\begin{gathered}
\Delta \widehat{O} \approx \Delta \widehat{S}_{k i n}+\Delta \widehat{S}_{m i x}+\Delta \widehat{R} \\
\Delta \widehat{O} \approx \underbrace{\Delta \widehat{S}_{k i n}^{\text {sol }}+\Delta \widehat{S}_{m i x}^{\text {sol }}}_{\text {solubility }}+\underbrace{\Delta \widehat{S}_{\text {kin }}^{\text {circ }}+\Delta \widehat{S}_{m i x}^{\text {circ }}}_{\text {circulation }}+\underbrace{\Delta \widehat{R}}_{\text {biology }}
\end{gathered}
$$

and:

$$
\begin{gathered}
\Delta \widehat{O}^{s a t} \approx \Delta \widehat{S}_{k i n}^{s o l}+\Delta \widehat{S}_{m i x}^{s o l} \\
-\Delta \widehat{A O U} \approx \Delta \widehat{S}_{k i n}^{c i r c}+\Delta \widehat{S}_{m i x}^{c i r c}+\Delta \widehat{R}
\end{gathered}
$$

This equivalence enables us to quantify the contributions of the changes in solubility, circulation and respiration to global deoxygenation, and the physical processes into play, i.e. kinematic or mixing.

\section{Results}

\subsection{Oxygen subduction and respiration in the preindustrial ocean}

In the CTL simulation which is close to equilibrium, the global net oxygen flux between the mixed-layer and below is close to zero. However regionally this is not the case, some regions are breathing in (i.e. gaining oxygen) while some are breathing out (i.e. losing oxygen), and the local balance is achieved through lateral oxygen fluxes below the mixed-layer. Here we present the pathways of these oxygen exchanges across the mixedlayer interface in this CTL simulation.

Kinematic subduction patterns in the CTL simulation (Fig. 1a) are characterized by net subduction in the subtropical gyres and polar regions, and net obduction over most 


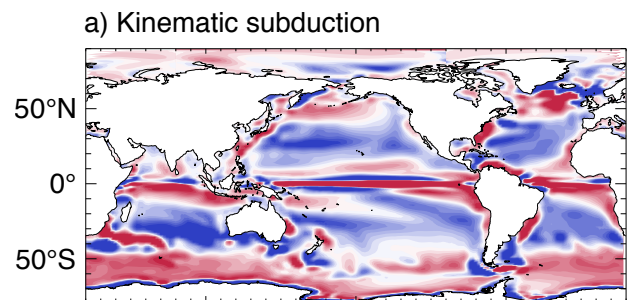

c) Respiration

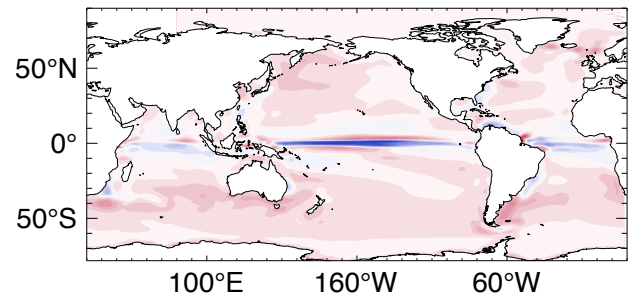

b) Diffusive subduction

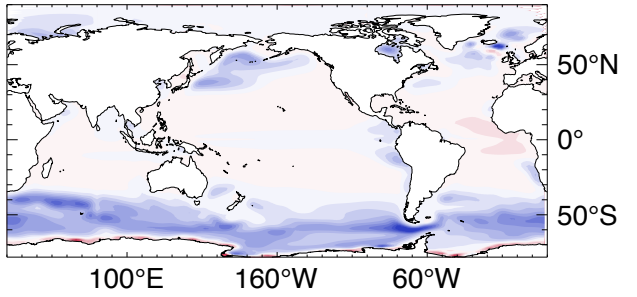

Deoxygenation $\quad \mathrm{molO}_{2} / \mathrm{m}^{2} \quad$ Oxygenation

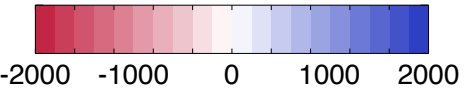

Figure 1. Spatial patterns of a) kinematic oxygen subduction $\left(S_{k i n}\right)$, b) diffusive oxygen subduction $\left(S_{m i x}\right)$ and c) respiration $(R)$ in the CTL simulation, cumulated over a period of 110 years, from 1990 until 2099. A Gaussian blur has been applied before plotting to smooth grid-point noise.

of the subpolar gyres and in the equatorial region. The largest values are found in areas of strong currents (Gulf Stream, Agulhas, Kuroshio) and along the coasts. These patterns mostly reflect those of water mass subduction (see for instance Lévy et al. (2013); Bopp et al. (2015)), and particularly the leading role of vertical Ekman velocities (Figs. S4,S5). Diffusive subduction (Fig. 1b) is positive at mid and high latitudes. This is due to oxygen being close to saturation in the mixed-layer and undersaturated below the mixedlayer, and thus to a negative vertical oxygen gradient across the mixed-layer (see for instance station 1 in Figs. S9,S10). The strongest values are found in the Southern Ocean (station 3 in Figs. S9,S10). We can note that the diffusive flux tends to oppose the kinematic flux in these regions. In contrast, diffusive subduction is negative (although close to zero) over subtropical regions. In these regions, due to lack of nutrients in the mixedlayer, photosynthesis is often maximum below the surface mixed-layer, leading to the production of oxygen at subsurface, oversaturation of oxygen below the mixed-layer and thus a reversal of the vertical oxygen gradient (station 2 in Figs. S9,S10). We can note that the contributions of vertical and lateral mixing to diffusive subduction (Fig. S5) have similar magnitudes and patterns. Respiration is almost uniformly negative (Fig. 1c, because of the large contribution of the sedimentation of particles. The positive values in the equatorial band are due to the obduction of organic matter (Fig. S6). On a zonal 
average, the mean preindustrial ocean is gaining oxygen in its interior in polar regions and the subtropical gyres, and losses oxygen in the equatorial band and in the subpolar gyres (Fig. 2a).

\subsection{Changes in oxygen subduction and respiration due to climate change}

In order to evaluate the subduction and respiration changes over the 21st century, the analysis presented for the CTL experiment are repeated for the CC experiment. This comparison reveals that the latitudinal patterns of subduction and respiration are very similar in the two experiments (Fig. 2a,b). Deoxygenation thus ensues from small variations (Fig. 2c) of large natural fluxes.

Kinematic subduction is the flux that shows the largest amplitude of changes, both positive and negative (Fig. 2c). In particular the obduction pattern located between $50 \mathrm{~S}$ and $60 \mathrm{~S}$ in the Southern ocean is slightly shifted to the South in the CC experiment, in response to a southward shift of the wind (Bracegirdle et al., 2013). More generally, changes in kinematic subduction are well explained by changes in wind patterns and associated Ekman velocities derived from the wind curl (Fig. S4b).

In contrast, changes in respiration and diffusive subduction are more uniform and tend to have a constant sign, with the exception of the Southern Ocean south of 50S. There is generally less respiration, leading to less oxygen consumption. The decrease in export production in response to climate change is a general feature of CMIP5 models, and a direct consequence to reduced nutrient supplies associated with increased stratification (Bopp et al., 2013; Laufkötter et al., 2015). In the Southern Ocean, the pattern of change is more complex because it integrates balancing effects of light and nutrient limitation (Laufkötter et al., 2015; Llort et al., 2019). This results in a small increase in respiration with climate change there.

There is also a general decrease in the diffusive subduction flux of oxygen, again with the exception of the Southern Ocean south of 50S. At high latitudes and in temperate regions where there was a net diffusive subduction of oxygen, the decrease essentially resulted from a decrease of the vertical gradient of oxygen at the mixed-layer base, in great part due to a decrease in the vertical gradient of AOU (station 1 in Figs. S9,S10 ). This decrease can be explained by the reduction in oxygen undersaturation below the mixed-layer, a direct consequence of the diminution in respiration. In the Southern Ocean, 


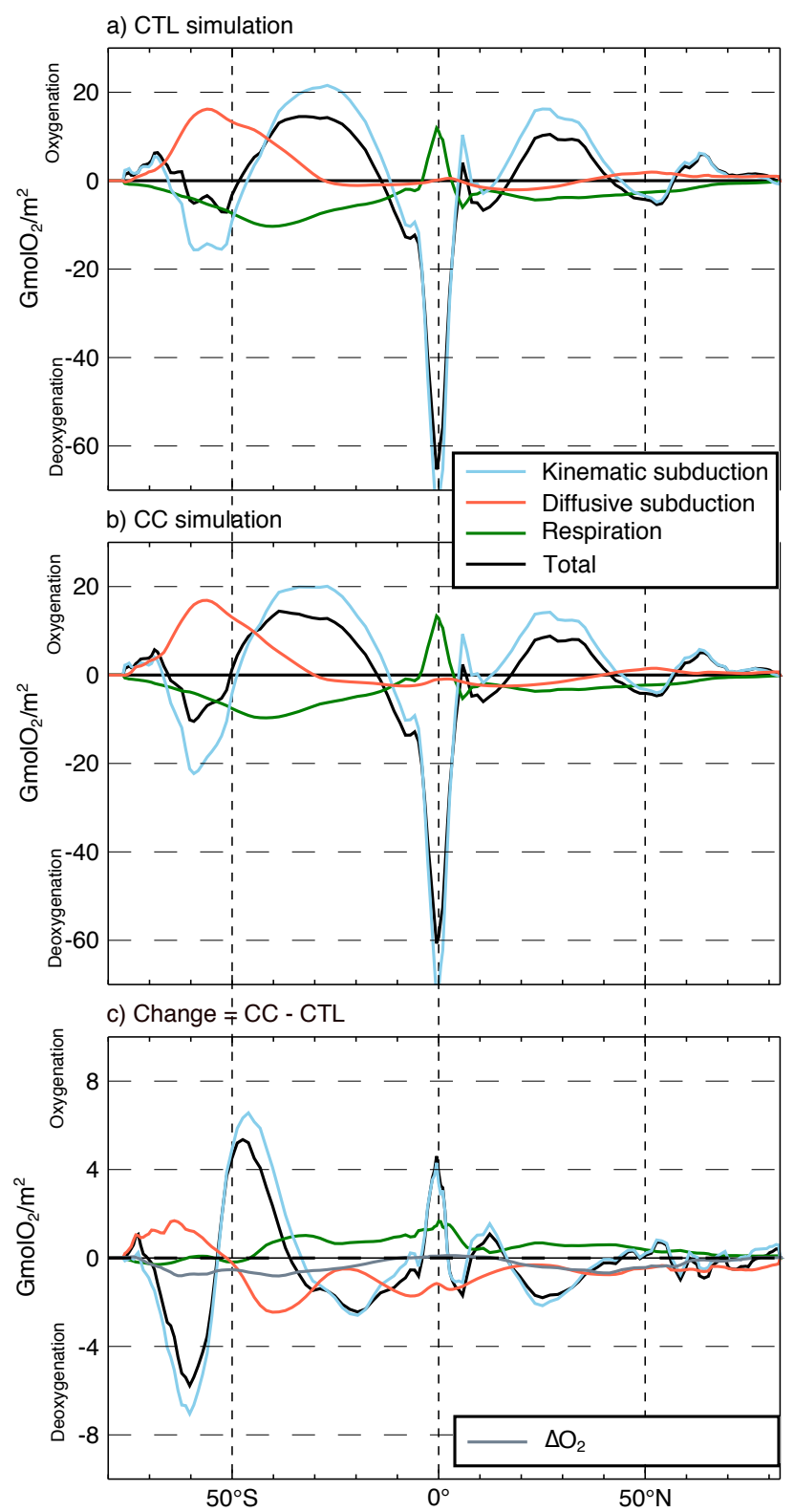

Figure 2. Zonal integral of kinematic oxygen subduction, diffusive oxygen subduction, respiration, and their sum (total), cumulated over a period of 110 years, from 1990 until 2099 a) in the CTL simulation, b) in the CC simulation and c) the difference between the two. The grey line in c) shows the change in oxygen content below the mixed-layer between the 2090s and the 1990s in the CC simulation corrected from the model drift in the CTL simulation. A running mean over $10^{\circ}$ in latitude is applied to all quantities before plotting. 
the gradient is increased due to an increase of undersaturation, which can be partly related with the increase in respiration (station 3 in Figs. S9,S10). In contrast, in the subtropical regions where there was a net diffusive obduction flux of oxygen, this net obduction was increased because of a deeper production of oxygen by photosynthesis, causing a weaker vertical oxygen gradient at the mixed-layer base (station 2 in Figs. S9,S10). All together (black line in Fig. 2c), the latitudinal patterns of changes are essentially driven by shifts in areas of kinematic obduction/subduction, and related with shifts in the wind curl.

Finally, figure 3a shows the global variations of kinematic subduction, diffusive subduction and respiration. First of all, we note that the variation of the sum of the three fluxes (black line in Fig. 3a) is close to the evolution of the subsurface oxygen content (dashed grey line), which provides further confidence in our offline estimates. This analysis enables us to fully quantify the contribution of the dynamical and biological processes responsible for deoxygenation in this model. We find that at the global scale, the 6.8 $\mathrm{Pmol} \mathrm{O}_{2}$ of deoxygenation in the ocean interior in this model result from a loss of more than twice this quantity by a reduction in total oxygen subduction $\left(-15.1 \mathrm{Pmol} \mathrm{O}_{2}\right)$, balanced by a reduction in respiration $\left(+8.3 \mathrm{Pmol}_{2}\right)$ which reduces net deoxygenation. Moreover, $3 / 4$ of the decrease in total oxygen subduction occurs through changes in mixing of $\mathrm{O}_{2}$ across the mixed-layer interface. Thus at the global scale, the dominant process responsible for deoxygenation is the reduction in the diffusive subduction of oxygen. This contrasts with the regional scale (Fig. 2c) where shifts in regions of kinematic obduction/subduction dominate.

Next we quantify the contributions of the changes in solubility and circulation (Fig. $3 \mathrm{~b}, \mathrm{c})$. We find that the solubility effect explains roughly half of deoxygenation. More precisely, changes in solubility explain $\sim 50 \%$ of the reduction in the kinematic subduction of oxygen, and $\sim 20 \%$ of the reduction in diffusive subduction. The other half of deoxygenation correspond to changes in AOU and are explained by a strong balance between changes due to circulation (kinematic $\sim+25 \%$ and diffusive $\sim+125 \%$ ) and changes in respiration $(\sim-100 \%)$. 
a) $\Delta \mathrm{O}_{2}$
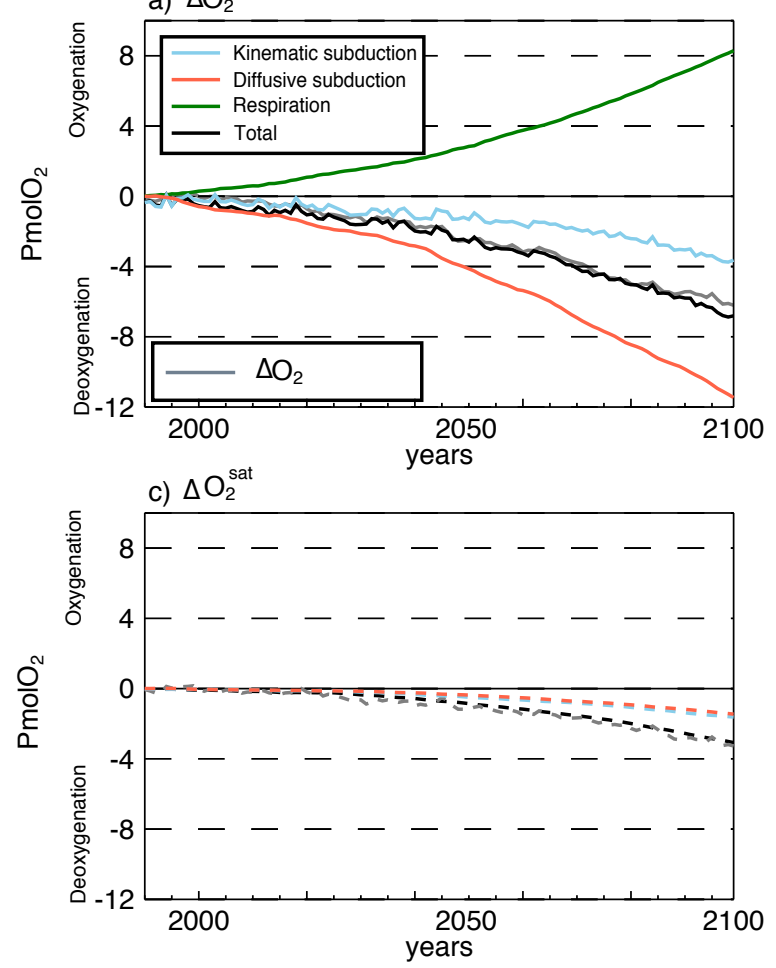

b) Cumulated contributions to $\Delta \mathrm{O}_{2}$ in 2100

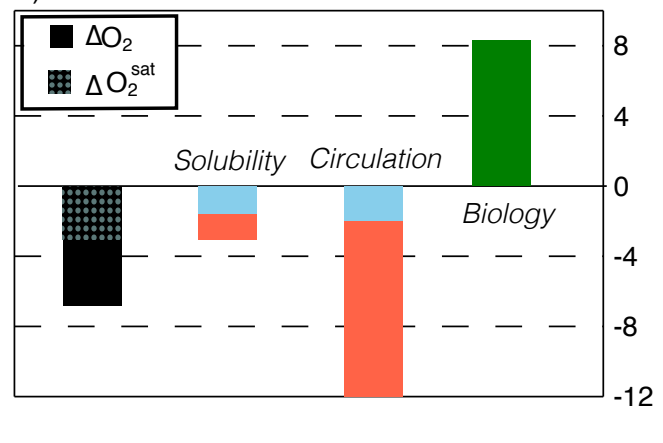

d) $-\triangle \mathrm{AOU}$

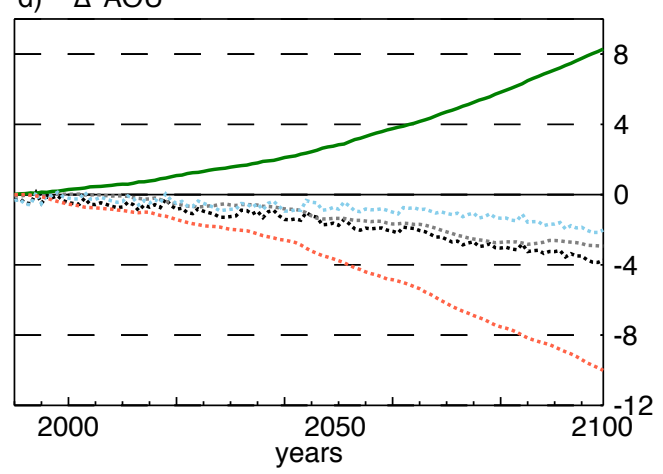

Figure 3. Factors explaining global deoxygenation along the 21st century in the IPSL-CM5ALR projection under scenario RCP8.5. a) Time cumulated evolution of kinematic subduction $\left(\Delta \widehat{S}_{k i n}\right.$, blue line), diffusive subduction $\left(\Delta \widehat{S}_{m i x}\right.$, red line), respiration ( $\Delta \widehat{R}$, green line), their sum (Total, black line) and changes in subsurface $\mathrm{O}_{2}\left(\Delta \widehat{O}_{2}\right.$, grey line) integrated over the global ocean. c) Same for changes due to solubility $\left(\Delta \widehat{S}_{k i n}^{\text {sol }}\right.$ and $\Delta \widehat{S}_{m i x}^{\text {sol }}$, dashed blue and red lines with their sum in dashed black) compared to changes in $\mathrm{O}_{2}^{\text {sat }}$ ( $\Delta \widehat{O}^{\text {sat }}$, dashed grey line). d) Same for changes due to circulation $\left(\Delta \widehat{S}_{k i n}^{\text {circ }}\right.$ and $\Delta \widehat{S}_{m i x}^{\text {circ }}$, dotted blue and red lines) and respiration $(\Delta \widehat{R}$, green line), with the sum of the three in dotted black, compared to changes in $\mathrm{AOU}(-\Delta A O U$, dotted grey line). b) Time cumulated contributions to global deoxygenation in 2100, sorted by solubility $\left(\Delta \widehat{S}_{m i x}^{\text {sol }}\right.$ and $\left.\Delta \widehat{S}_{k i n}^{\text {sol }}\right)$, circulation $\left(\Delta \widehat{S}_{m i x}^{\text {circ }}\right.$ and $\left.\Delta \widehat{S}_{k i n}^{\text {circ }}\right)$ and biology $(\Delta \widehat{R})$, compared to global deoxygenation $\left(\Delta \widehat{O_{2}}\right)$ and $\Delta \widehat{O}^{\text {sat }}$. 


\section{Discussion and conclusion}

Using simulations carried out with the IPSL ESM, we present a quantitative assessment of the thermodynamical, physical and biological drivers of future global deoxygenation, which is based on the analysis of changes in the rates of oxygen transport from the surface ocean into its interior, i.e. in the changes of how the ocean breathes in and breathes out (Fig. 2). At the global scale, and in agreement with previous estimates, we find that the decrease in solubility explains roughly half of subsurface deoxygenation (Keeling et al., 2010; Schmidtko et al., 2017; Resplandy, 2018). In addition, our results show that the other half consists in a balance between large negative trends in the physical supply of oxygen and in subsurface respiration, which largely cancel out each other (Fig. 3). Another important result is the first order contribution of reduced oxygen penetration through mixing across the mixed-layer base. This is despite oxygen mixing being a much smaller contributor than kinematic subduction for surface/subsurface oxygen exchanges over most oceanic regions (Fig. 1). In the North Pacific, this agrees with results from a similar analysis performed with a regional model constrained to historical variability using an assimilation technique (Kwon et al., 2016). Our conclusion on the leading role of mixing is complementary to that of Palter and Trossman (2018) in that they focused on mixing in the ocean interior. It is often assumed that increased stratification in response to ocean warming would reduce oxygen penetration in the ocean. In our offline diagnostics, this effect was not directly accounted for since we kept the same strength of mixing across the mixed-layer base. However our study shows that changes in AOU gradient across the mixed-layer base in itself contribute to the oxygen mixing reduction. What controls the change in this gradient is beyond the scope of this study, but from a few examples (Figs S9,S10) we can hypothesize that changes in biological activity and meridional transport both play a role. At the regional scale, subduction changes are very heterogeneous and mainly reflect shifts in vertical advection which are linked to changes in wind curl patterns, thus changes in circulation often prevail over changes in mixing. We find the effect to be particularly strong in the Southern Ocean, but also in the North Atlantic and North Pacific, where previous regional studies had already identified shifts in the main current systems as important drivers of local changes (Kwon et al., 2016; Tagklis et al., 2017).

A natural question is the robustness and inherent limits of this quantification. From a purely computational point of view, there are inherent errors associated with the of- 
fline approach related to the use of model-output monthly averages, interpolated mixedlayer depths and different numerical schemes between online (implicit, positive with flux correction on a C-grid) and offline (explicit, no flux correction, depth interpolated values). Since our subsurface oxygen budget is nearly closed (as revealed by the close correspondence between the black and grey lines in Fig. 3), it is likely that the errors are small with potentially some compensations. Nevertheless we have attempted to estimate the magnitude of our errors with a forced preindustrial simulation run with the same NEMOPISCES model in which subduction and sedimentation rates were computed online at each model time step and compared to offline diagnostics that used monthly model outputs. Globally, the offline and online estimates differed by only $\sim 10 \%$ but there were larger differences locally and for each term taken individually (Fig. S2). To compute respiration, we also relied on the assumption of a mean carbon to oxygen ratio of 160/132, related to the partitioning of oxic remineralization and denitrification in our modelled ocean. A choice slightly different $( \pm 10 / 132)$ would lead to a difference of $\pm 6 \%$ on the global cumulated change in respiration. Finally, our results emphasize a leading role for the change in vertical mixing, but our estimate of this term depends strongly on the value of the vertical mixing coefficient at the mixed-layer base, which we have estimated under the constrain that the online and offline estimates of oxygen vertical mixing in our forced preindustrial simulations should be equal. In a warming ocean, it is expected that enhanced stratification will inhibit vertical mixing (Capotondi et al., 2012), and this may result in weaker vertical mixing at the mixed-layer base. This point would need to be confirmed by dedicated studies, and the potential effect, if present in the online simulation, has not been accounted for the offline estimate.

From a modelling point of view, the coarse resolution of the model does not allow for an explicit representation of eddy fluxes that have been shown to contribute significantly to oxygen budgets in dedicated regional studies (Resplandy et al., 2012; Lachkar et al., 2016; Thomsen et al., 2016). It is still questionable that the eddy parametrization used in the model represents these fluxes correctly. Although an interesting characteristic of the IPSL-CM5A-LR RCP8.5 projection is that the oxygen change simulated in the mesopelagic layer between the 1990s and 2090s is a fair representation of the mean change projected by the other CMIP5 models (Fig. S1a-d), our results would be stronger if the method could have been applied to all ten model members of the climate-biogeochemical CMIP5 climate change simulations. However the methodology requires monthly outputs 
which were not part of the CMIP5 output protocol (these monthly 3D output fields are required by the CMIP6 protocol as detailled in Orr et al. (2017)). At that stage, the quantification could only be based on outputs from our home experiment IPSL-CM5A-LR for which the monthly time resolution was available. We should note that the method could also be extended to observations (see Lévy et al. (2013)).

Moreover, there are some bias in this model in representing the vertical gradients of $\mathrm{O}_{2}$ in the pre-industrial state, which can be sharper than in the Word Ocean Atlas climatology (see for instance Fig. S8), with direct consequences on the estimate of $\mathrm{O}_{2}$ vertical mixing.

Finally from a more conceptual point of view, the main limitation of this approach is that it cannot explain the details of the vertical structure of deoxygenation below the mixed-layer, which depends of the redistribution of the changes in the ocean interior after subduction and export. Understanding the drivers of the critical changes in the volume of suboxic waters, for example, requires a complete analysis of the subsurface oxygen budget (Gnanadesikan et al., 2012; Oschlies et al., 2017; Llanillo et al., 2018; Lachkar et al., 2018). Overall, our results highlight the crucial need to correctly resolve ocean circulation and near surface oxygen gradients in order to gain confidence in our projections of future deoxygenation.

\section{Acknowledgments}

DC received a PhD grant from Sorbonne Université. This work was supported by CNES (TOSCA proposal CLIMCOLOR), by H2020-CRESCENDO grant and by ANR project SOBUMS (ANR-16-CE01-0014). The authors thank Christian Ethe who helped with the implementation of the subduction diagnostics. The authors acknowledge IPSL-CMC for supplying the data and the data center ESPRI/IPSL for their help in accessing the data. Data available online: https://doi.org/10.14768/20190625001.1. Diagnostics code available online https://github.com/damiencouespel/oxygen_subduction_diagnostics.

\section{References}

Aumont, O., \& Bopp, L. (2006). Globalizing results from ocean in situ iron fertilization studies. Global Biogeochemical Cycles, 20(2), GB2017. doi: 10.1029/ 2005GB002591 
Aumont, O., Ethé, C., Tagliabue, A., Bopp, L., \& Gehlen, M. (2015). PISCES-v2: an ocean biogeochemical model for carbon and ecosystem studies. Geoscientific Model Development, 8(8), 2465-2513. doi: 10.5194/gmd-8-2465-2015

Bao, Y., \& Li, Y. (2016, dec). Simulations of dissolved oxygen concentration in CMIP5 Earth system models. Acta Oceanologica Sinica, 35(12), 28-37. doi: 10 $.1007 / \mathrm{s} 13131-016-0959-\mathrm{x}$

Bopp, L., Lévy, M., Resplandy, L., \& Sallée, J.-B. (2015). Pathways of anthropogenic carbon subduction in the global ocean. Geophysical Research Letters, 42(15), 6416-6423. doi: 10.1002/2015GL065073

Bopp, L., Resplandy, L., Orr, J. C., Doney, S. C., Dunne, J. P., Gehlen, M., ... Vichi, M. (2013). Multiple stressors of ocean ecosystems in the 21st century: projections with CMIP5 models. Biogeosciences, 10(10), 6225-6245. doi: $10.5194 /$ bg-10-6225-2013

Bopp, L., Resplandy, L., Untersee, A., Le Mezo, P., \& Kageyama, M. (2017). Ocean (de)oxygenation from the Last Glacial Maximum to the 21st century: insights from Earth System Models. Philosophical Transactions of the Royal Society A: Mathematical, Physical and Engineering Sciences, 375(2102). doi: $10.1098 /$ rsta.2016.0323

Bracegirdle, T. J., Shuckburgh, E., Sallee, J. B., Wang, Z., Meijers, A. J., Bruneau, N., .. Wilcox, L. J. (2013). Assessment of surface winds over the atlantic, indian, and pacific ocean sectors of the southern ocean in cmip5 models: Historical bias, forcing response, and state dependence. Journal of Geophysical Research Atmospheres, 118(2), 547-562. doi: 10.1002/jgrd.50153

Breitburg, D., Levin, L. A., Oschlies, A., Grégoire, M., Chavez, F. P., Conley, D. J., ... Zhang, J. (2018). Declining oxygen in the global ocean and coastal waters. Science, 359(6371), eaam7240. doi: 10.1126/science.aam7240

Cabré, A., Marinov, I., Bernardello, R., \& Bianchi, D. ～(2015). Oxygen minimum zones in the tropical Pacific across CMIP5 models: mean state differences and climate change trends. Biogeosciences, 12(18), 5429-5454. doi: $10.5194 /$ bg-12-5429-2015

Capotondi, A., Alexander, M. A., Bond, N. A., Curchitser, E. N., \& Scott, J. D. (2012). Enhanced upper ocean stratification with climate change in the CMIP3 models. Journal of Geophysical Research: Oceans, 117(C4), C04031. doi: 
10.1029/2011JC007409

Ciais, P., Sabine, C., Bala, G., Bopp, L., Brovkin, V., Canadell, J., ... Thornton, P. (2013). Carbon and Other Biogeochemical Cycles. In V. B. Stocker, T.F., D. Qin, G.-K. Plattner, M. Tignor, S.K. Allen, J. Boschung, A. Nauels, Y. Xia \& P. Midgley (Eds.), Climate change 2013: The physical science basis. contribution of working group $i$ to the fifth assessment report of the intergovernmental panel on climate change (pp. 465-570). Cambridge University Press, Cambridge, United Kingdom and New York, NY, USA. doi: 10.1017/CBO9781107415324.015

Cocco, V., Joos, F., Steinacher, M., Frölicher, T. L., Bopp, L., Dunne, J. P., .. . Tjiputra, J. (2013). Oxygen and indicators of stress for marine life in multimodel global warming projections. Biogeosciences, 10(3), 1849-1868. doi: $10.5194 /$ bg-10-1849-2013

Codispoti, L. A., Brandes, J. A., Christensen, J. P., Devol, A. H., Naqvi, S. W. A., Paerl, H. W., \& Yoshinari, T. (2001). The oceanic fixed nitrogen and nitrous oxide budgets: Moving targets as we enter the anthropocene? Scientia Marina, 65(S2), 85-105. doi: 10.3989/scimar.2001.65s285

Cushman-Roisin, B. (1987). Subduction. In Dynamics of the oceanic surface mixed layer (pp. 1-17).

Deutsch, C., Emerson, S., \& Thompson, L. (2005). Fingerprints of climate change in North Pacific oxygen. Geophysical Research Letters, 32(16), L16604. doi: 10 $.1029 / 2005$ GL023190

Deutsch, C., Emerson, S., \& Thompson, L. (2006). Physical-biological interactions in North Pacific oxygen variability. Journal of Geophysical Research: Oceans, 111 (C9), C09S90. doi: 10.1029/2005JC003179

Diaz, R. J., \& Rosenberg, R. (2008). $\quad$ Spreading Dead Zones and Consequences for Marine Ecosystems. S Science, 321(5891), 926-929. doi: 10.1126/science .1156401

Dufresne, J.-L., Foujols, M. A., Denvil, S., Caubel, A., Marti, O., Aumont, O., ... Vuichard, N. (2013). Climate change projections using the IPSL-CM5 Earth System Model: from CMIP3 to CMIP5. C Climate Dynamics, 40(9-10), 21232165. doi: $10.1007 / \mathrm{s} 00382-012-1636-1$

Fu, W., Primeau, F., Keith Moore, J., Lindsay, K., \& Randerson, J. T. 
Reversal of Increasing Tropical Ocean Hypoxia Trends With Sustained

Climate Warming. Global Biogeochemical Cycles, 32(4), 551-564.

doi: 10.1002/2017GB005788

Garcia, H. E., \& Gordon, L. I. (1992). Oxygen solubility in seawater: Better fitting equations. Limnology and Oceanography, 37(6), 1307-1312. doi: 10.4319/lo .1992 .37 .6 .1307

Gent, P. R., \& McWilliams, J. C. (1990). Isopycnal Mixing in Ocean Circulation Models. Journal of Physical Oceanography, 20, 150-160. doi: 10.1175/1520 -0485(1990)020〈0150:IMIOCM $>2.0 . C O ; 2$

Gnanadesikan, A., Dunne, J. P., \& John, J. ～(2012). Understanding why the volume of suboxic waters does not increase over centuries of global warming in an Earth System Model. Biogeosciences, 9(3), 1159-1172. doi: 10.5194/bg-9-1159-2012

Helm, K. P., Bindoff, N. L., \& Church, J. A. (2011). Observed decreases in oxygen content of the global ocean. Geophysical Research Letters, 38(23), L23602. doi: 10.1029/2011GL049513

Ito, T., Minobe, S., Long, M. C., \& Deutsch, C. (2017). Upper ocean O2 trends: 1958\{\textendash\}2015. Geophysical Research Letters, 44(9), 4214-4223. doi: 10.1002/2017GL073613

Karleskind, P., Lévy, M., \& Mémery, L. (2011). Subduction of carbon, nitrogen, and oxygen in the northeast Atlantic. Journal of Geophysical Research: Oceans, 116(C2), C02025. doi: 10.1029/2010JC006446

Keeling, R. F., Körtzinger, A., \& Gruber, N. (2010). Ocean deoxygenation in a warming world. Annual review of marine science, 2, 199-229. doi: 10.1146/ annurev.marine.010908.163855

Kwon, E. Y., Deutsch, C., Xie, S.-P., Schmidtko, S., \& Cho, Y.-K. (2016). The North Pacific Oxygen Uptake Rates over the Past Half Century. Journal of Climate, 29, 61-76. doi: 10.1175/JCLI-D-14-00157.1

Lachkar, Z., Lévy, M., \& Smith, S. (2018). Intensification and deepening of the Arabian Sea oxygen minimum zone in response to increase in Indian monsoon wind intensity. Biogeosciences, 15(1), 159-186. doi: 10.5194/bg-15-159-2018

Lachkar, Z., Smith, S. K., Lévy, M., \& Pauluis, O. (2016). Eddies reduce denitrification and compress habitats in the Arabian Sea. Geophysical Research Letters, 
43(17), 9148-9156. doi: 10.1002/2016GL069876

Laufkötter, C., Vogt, M., Gruber, N., Aita-Noguchi, M., Aumont, O., Bopp, L., ... Völker, C. (2015). Drivers and uncertainties of future global marine primary production in marine ecosystem models. Biogeosciences Discussions, 12(23), 6955-6984. doi: 10.5194/bgd-12-3731-2015

Leung, S., Cabré, A., \& Marinov, I. ～(2015). A latitudinally banded phytoplankton response to 21st century climate change in the Southern Ocean across the CMIP5 model suite. Biogeosciences, 12(19), 5715-5734. doi: $10.5194 /$ bg-12-5715-2015

Lévy, M., Bopp, L., Karleskind, P., Resplandy, L., Ethé, C., \& Pinsard, F. (2013). Physical pathways for carbon transfers between the surface mixed layer and the ocean interior. Global Biogeochemical Cycles, 27(4), 1001-1012. doi: $10.1002 /$ gbc. 20092

Little, C. M., \& Urban, N. M. (2016). CMIP5 temperature biases and 21st century warming around the Antarctic coast. Annals of Glaciology, 57(73), 69-78. doi: 10.1017/aog.2016.25

Llanillo, P. J., Pelegr \’i, J. L., Talley, L. D., Peña-Izquierdo, J., \& Cordero, R. R. (2018). Oxygen Pathways and Budget for the Eastern South Pacific Oxygen Minimum Zone. Journal of Geophysical Research: Oceans, 123(3), 1722-1744. doi: 10.1002/2017JC013509

Llort, J., Lévy, M., Sallée, J. B., \& Tagliabue, A. (2019). Nonmonotonic Response of Primary Production and Export to Changes in Mixed-Layer Depth in the Southern Ocean. Geophysical Research Letters, 46(6), 3368-3377. doi: 10.1029/2018GL081788

Orr, J. C., Najjar, R. G., Aumont, O., Bopp, L., Bullister, J. L., Danabasoglu, G., ... Yool, A. (2017). Biogeochemical protocols and diagnostics for the CMIP6 Ocean Model Intercomparison Project (OMIP). Geoscientific Model Development, 10 (6), 2169-2199. doi: 10.5194/gmd-10-2169-2017

Oschlies, A., Duteil, O., Getzlaff, J., Koeve, W., Landolfi, A., \& Schmidtko, S. (2017). Patterns of deoxygenation: sensitivity to natural and anthropogenic drivers. Philosophical Transactions of the Royal Society A: Mathematical, 375(2102), 20160325. doi: 10.1098/rsta.2016.0325

Palter, J. B., \& Trossman, D. S. (2018). The sensitivity of future ocean oxygen 
to changes in ocean circulation. Global Biogeochemical Cycles, 32(5), 738-751. doi: 10.1002/2017GB005777

Resplandy, L. (2018). Will ocean zones with low oxygen levels expand or shrink? Nature, 557(7705), 314-315. doi: 10.1038/d41586-018-05034-y

Resplandy, L., Lévy, M., Bopp, L., Echevin, V., Pous, S., Sarma, V. V. S. S., \& Kumar, D. (2012). Controlling factors of the oxygen balance in the Arabian Sea's OMZ. Biogeosciences, 9(12), 5095-5109. doi: 10.5194/bg-9-5095-2012

Schmidtko, S., Stramma, L., \& Visbeck, M. (2017). Decline in global oceanic oxygen content during the past five decades. Nature Publishing Group, 542(7641), 335-339. doi: 10.1038/nature21399

Shepherd, J. G., Brewer, P. G., Oschlies, A., \& Watson, A. J. (2017). Ocean ventilation and deoxygenation in a warming world: introduction and overview. Philosophical Transactions of the Royal Society A: Mathematical, Physical and Engineering Sciences, 375(2102), 20170240. doi: 10.1098/rsta.2017.0240

Shu, Q., Song, Z., \& Qiao, F. (2015). Assessment of sea ice simulations in the CMIP5 models. The Cryosphere, 9(1), 399-409. doi: 10.5194/tc-9-399-2015

Stendardo, I., \& Gruber, N. (2012). Oxygen trends over five decades in the North Atlantic. Journal of Geophysical Research: Oceans, 117(C11), C11004. doi: 10 $.1029 / 2012 J C 007909$

Tagklis, F., Bracco, A., \& Ito, T. (2017). Physically driven patchy O2 changes in the North Atlantic Ocean simulated by the CMIP5 Earth system models. Global Biogeochemical Cycles, 31(8), 1218-1235. doi: 10.1002/2016GB005617

Takano, Y., Ito, T., \& Deutsch, C. (2018). Projected Centennial Oxygen Trends and Their Attribution to Distinct Ocean Climate Forcings.

Global Biogeochemical Cycles, 32(9), 1329-1349. doi: 10.1029/2018GB005939

Thomsen, S., Kanzow, T., Colas, F., Echevin, V., Krahmann, G., \& Engel, A.

(2016). Do submesoscale frontal processes ventilate the oxygen minimum zone off Peru? Geophysical Research Letters, 43(15), 8133-8142. doi: 10.1002/2016GL070548

Turner, J., Bracegirdle, T. J., Phillips, T., Marshall, G. J., \& Hosking, J. S. (2013). An Initial Assessment of Antarctic Sea Ice Extent in the CMIP5 Models. Journal of Climate, 26(5), 1473-1484. doi: 10.1175/JCLI-D-12-00068.1

Vaquer-Sunyer, R., \& Duarte, C. M. (2008). Thresholds of Hypoxia for Marine Bio- 
diversity. Proceedings of the National Academy of Sciences of the United States of America, 105 (40), 15452-15457. doi: 10.1073/pnas.0803833105

Yang, C.-Y., Liu, J., Hu, Y., Horton, R. M., Chen, L., \& Cheng, X. (2016). Assessment of Arctic and Antarctic sea ice predictability in CMIP5 decadal hindcasts. The Cryosphere, 10(5), 2429-2452. doi: 10.5194/tc-10-2429-2016 